\title{
Orientopius Fischer (Hymenoptera, Braconidae, Opiinae) new for Europe, with first notes on its biology and description of a new species
}

\author{
Cornelis van Achterberg ${ }^{1, \dagger}$, Jean-Luc Gumez ${ }^{2, \ddagger}$, \\ Michel Martinez, ${ }^{3, \S}$ Jean-Yves Rasplus, 3
}

I Department of Terrestrial Zoology, NCB Naturalis, Postbus 9517, 2300 RA Leiden, The Netherlands 2 154, rue Aristide Briand, 59540 Caudry, France 3 INRA, UMR Centre de Biologie pour la Gestion des Populations, F-34988 Montferrier-sur-Lez, France

† urn:lsid:zoobank.org:author:D6374CF4-8F07-4FA8-8C55-9335FD19CECD

† urn:lsid:zoobank.org:author:96935C26-CA3D-4136-86D5-488BD2491ECD

§ urn:lsid:zoobank.org:author:0B98E5C5-397F-4715-88FC-146F3C487321

II urn:lsid:zoobank.org:author:981D4685-5DA3-44AD-B056-CA5877F06329

Corresponding author: Cornelis van Achterberg (Cees.vanAchterberg@ncbnaturalis.nl)

Academic editor: Gavin Broad | Received 23 March 2012 | Accepted 2 July 2012 | Published 24 August 2012

urn:lsid:zoobank.org:pub:OFFOF226-ABD1-452E-8735-8D7464A11C4B

Citation: Achterberg C van, Gumez J-L, Martinez M, Rasplus J-Y (2012) Orientopius Fischer (Hymenoptera, Braconidae, Opiinae) new for Europe, with first notes on its biology and description of a new species. Journal of Hymenoptera Research 28: 123-134. doi: 10.3897/JHR.28.3118

\begin{abstract}
The genus Orientopius Fischer, 1966 (Hymenoptera: Braconidae: Opiinae) is reported for the first time from Europe and the West Palaearctic region, its biology (parasitoids of Phytobia spp.) is given for the first time and a new species (O. europaeus sp. n.) is described from France and Bulgaria.
\end{abstract}

\section{Keywords}

Braconidae, Opiinae, Orientopius, new species, Epimicta, Trachionus, Palaearctic, Europe, Bulgaria, France, biology, Phytobia spp., Diptera, Agromyzidae, Crataegus monogyna, Prunus spinosa

\section{Introduction}

The large subfamily Opiinae (Braconidae), with 1,975 valid species according to Yu et al. (2009), is a common group containing generally small $(2-5 \mathrm{~mm})$ parasitoid wasps

Copyright Cornelis van Achterberg et al. This is an open access article distributed under the terms of the Creative Commons Attribution License 3.0 (CC-BY), which permits unrestricted use, distribution, and reproduction in any medium, provided the original author and source are credited. 
of mainly mining or fruit-infesting dipterous larvae. It has a worldwide distribution and the world fauna has been reviewed by Fischer $(1972,1977,1986,1987)$. Currently about 35 genera are used, but the number of genera and the limits of several genera are still matters of discussion. The genus Orientopius Fischer, 1966, is a small genus with 13 described species from the East Palaearctic, Oriental and Australian (New Guinea) regions. Up to now, its biology was unknown; the metasomal carapace may indicate that oviposition is through e.g. a woody substrate or an egg-shell, both difficult to penetrate.

The second and third authors reared a new species of Orientopius from two species of the genus Phytobia Lioy, 1864 (Diptera: Agromyzidae) mining in the cambium of trees and shrubs of Crataegus monogyna Linnaeus and Prunus spinosa Linnaeus in northern France. The same species was collected in Central Bulgaria by the first author. Opiinae are solitary koinobiont endoparasitoids of larvae of cyclorrhaphous Diptera, but oviposition may take place into the egg of the host (ovo-larval parasitoids). They may play an important role in the control of dipterous pests such as fruit-infesting Tephritidae and mining Agromyzidae. The parasitoid larva has its final development when the host larva has made its puparium, and the adult parasitoid emerges from the host puparium.

\section{Material and methods}

The larvae and pupae of Phytobia were collected by J.L. Gumez in North France (Aisne, Bouconville-Vauclair, forêt domaniale de Vauclair and forêt domaniale de Samoussy). Some puparia were collected directly from the soil under the host plants (Fig. 30), others were obtained from young seedlings of Crataegus monogyna and Prunus spinosa with larvae at the ends of their branches. The infested branches were cut and placed in containers to obtain the puparia. These puparia were kept indoors under semi-natural conditions by the second and third authors to obtain adults of the Phytobia miner and its parasitoids. The identifications of the larvae and adults of Phytobia were made by M. Martinez and of the parasitoids by the first and last authors. Beside the fairly large series of Braconidae (10-20 specimens per species) some Ichneumonidae were reared, but these (together with more recently reared Phytobia parasitoids) will be treated in a second paper dealing with all reared material of Phytobia spp. in North France.

The specimens are deposited in the collection INRA (CBGP) at Montpellier and in the NCB Naturalis collection (RMNH) at Leiden. For identification of the subfamily Opiinae, see van Achterberg $(1990,1993,1997)$, for identification of the genus, see Fischer (1966), Tobias (1998) and Chen and Weng (2005), for references to the Opiinae, see Yu et al. (2009) and for the terminology used in this paper, see van Achterberg $(1988,1993)$. Measurements are taken as indicated by van Achterberg (1988). 


\section{Orientopius Fischer, 1966}

http://species-id.net/wiki/Orientopius

Figs 1-33

Type species. Orientopius curiosigaster Fischer, 1966 (original designation).

Diagnosis. Clypeus truncate medio-ventrally (Figs 6, 20); labrum exposed (Figs $20,22)$; occipital carina present latero-dorsally and weakly or not protruding in lateral view (Figs 2, 13, 23); head comparatively long in anterior view (Figs 6, 20) and malar space longer than basal width of mandible (Figs 13, 22); malar suture complete and distinctly impressed (Figs 6, 22); inner sides of antennal sockets normal, not protruding (Fig. 10); around base of middle coxa no circular carina; medio-posterior depression of mesoscutum present (Figs 7, 16, 33); notauli absent posteriorly or as row of punctures (Figs 7, 16, 33); postpectal carina variable, usually partly present medioventrally; vein 3-SR of fore wing about as long as vein 2-SR (Figs 3, 15, 32); metasoma with carapace (Figs 1, 2, 18, 32, 33), but less developed in males (Figs 13, 14); second tergite sculptured and distinctly longer than third tergite (Figs 1, 2, 14, 18, 32, 33); dorsal carinae of first tergite variable, separated basally (Fig. 14) or medially united in a median carina (Fig. 18); second metasomal suture distinctly crenulate (Figs 14, 18); third tergite of female with a sharp lateral crease (Figs 1, 2, 32).

Notes. Orientopius Fischer, 1966, is closely related to Coleopius Fischer, 1964; both have the female metasomal carapace covering the fourth and following tergites, the second metasomal tergite distinctly (1.3-1.9 times) longer than the third tergite, the third tergite with a sharp lateral crease and the second submarginal cell of the fore wing short. They can be separated as follows:

1 Malar suture complete and distinctly impressed; medio-posterior depression of mesoscutum present; second metasomal suture distinctly crenulate

Orientopius Fischer

- Malar suture incomplete and obsolescent; medio-posterior depression of mesoscutum absent; second metasomal suture finely sculptured, without distinct crenulae

Coleopius Fischer

\section{Orientopius europaeus van Achterberg, sp. n.}

urn:lsid:zoobank.org:act:6A85FD4E-3487-4F92-91EE-28452FB05EE2

http://species-id.net/wiki/Orientopius_europaeus

Figs 1, 2, 15-25, 32, 33

Type material. Holotype (RMNH),, , "C. Bulgaria, Bania, nr [= between Panagyurishte and] Pazardzhik, 25.VII.-10.VIII.2006, c. 500 m, Malaise trap in garden, C. v. Achterberg, RMNH'06”. Paratypes (INRA (CBGP), RMNH: 13 \%): 1 q, “[N. 


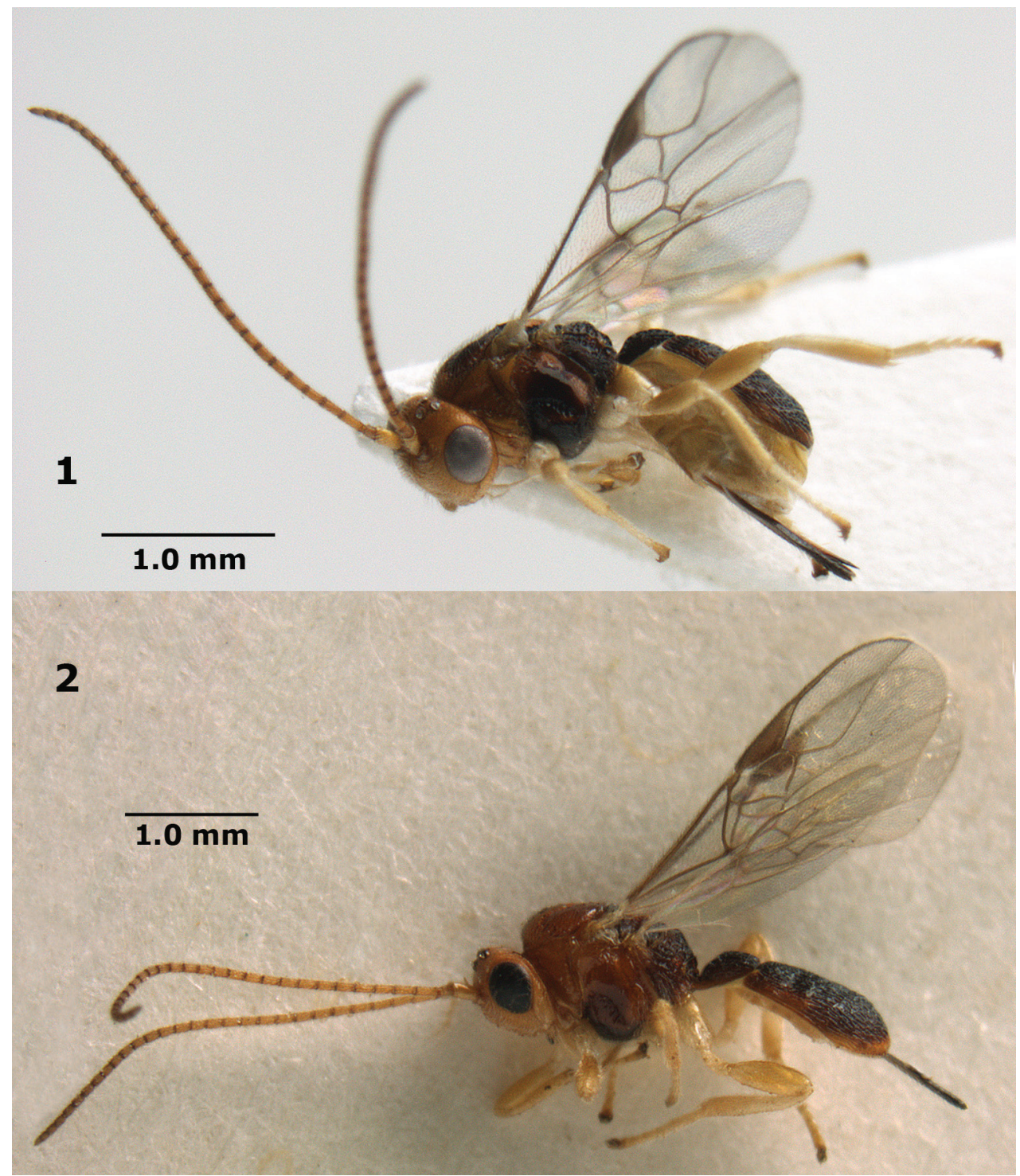

Figures I-2. Orientopius europaeus sp. n., female, holotype (upper) and paratype. Habitus lateral.

France], Aisne (02), Bouconville-Vauclair, forêt domaniale de Vauclair, J.L. Gumez", "pupe le 23.V.1990, éclos sous abri le 15.VI.1990", "Ex pupe de Phytobia carbonaria (Zetterstedt) sur Crataegus monogyna"; 1 , "[N. France], Aisne (02), BouconvilleVauclair, forêt domaniale de Vauclair, J.L. Gumez”, “pupe le 18.VII.1990, éclos sous abri le 9.X.1990", "Ex pupe de Phytobia cerasiferae (Kangas) sur Prunus spinosa"; 1 +, “[N. France], Aisne 02, Bouconville-Vauclair, forêt domaniale de Vauclair, J.L. 

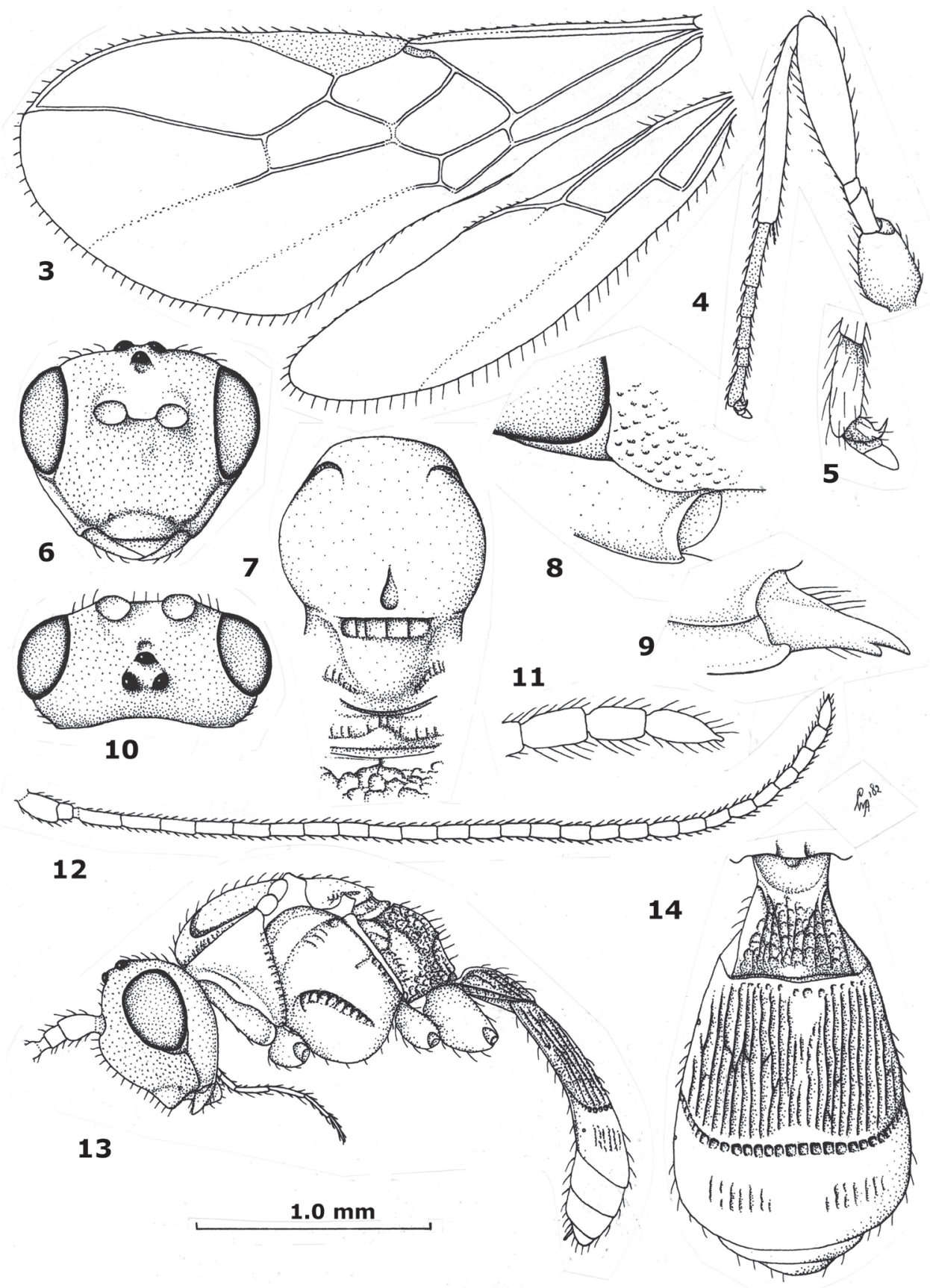

Figures 3-14. Orientopius curiosigaster Fischer, male, holotype. $\mathbf{3}$ wings $\mathbf{4}$ hind leg $\mathbf{5}$ outer hind claw $\mathbf{6}$ head anterior $\mathbf{7}$ mesosoma dorsal $\mathbf{8}$ malar space $\mathbf{9}$ mandible and ventral part of occipital carina $\mathbf{1 0}$ head dorsal I I apex of antenna I $\mathbf{2}$ antenna $\mathbf{3}$ habitus lateral I $\mathbf{4}$ metasoma dorsal. 


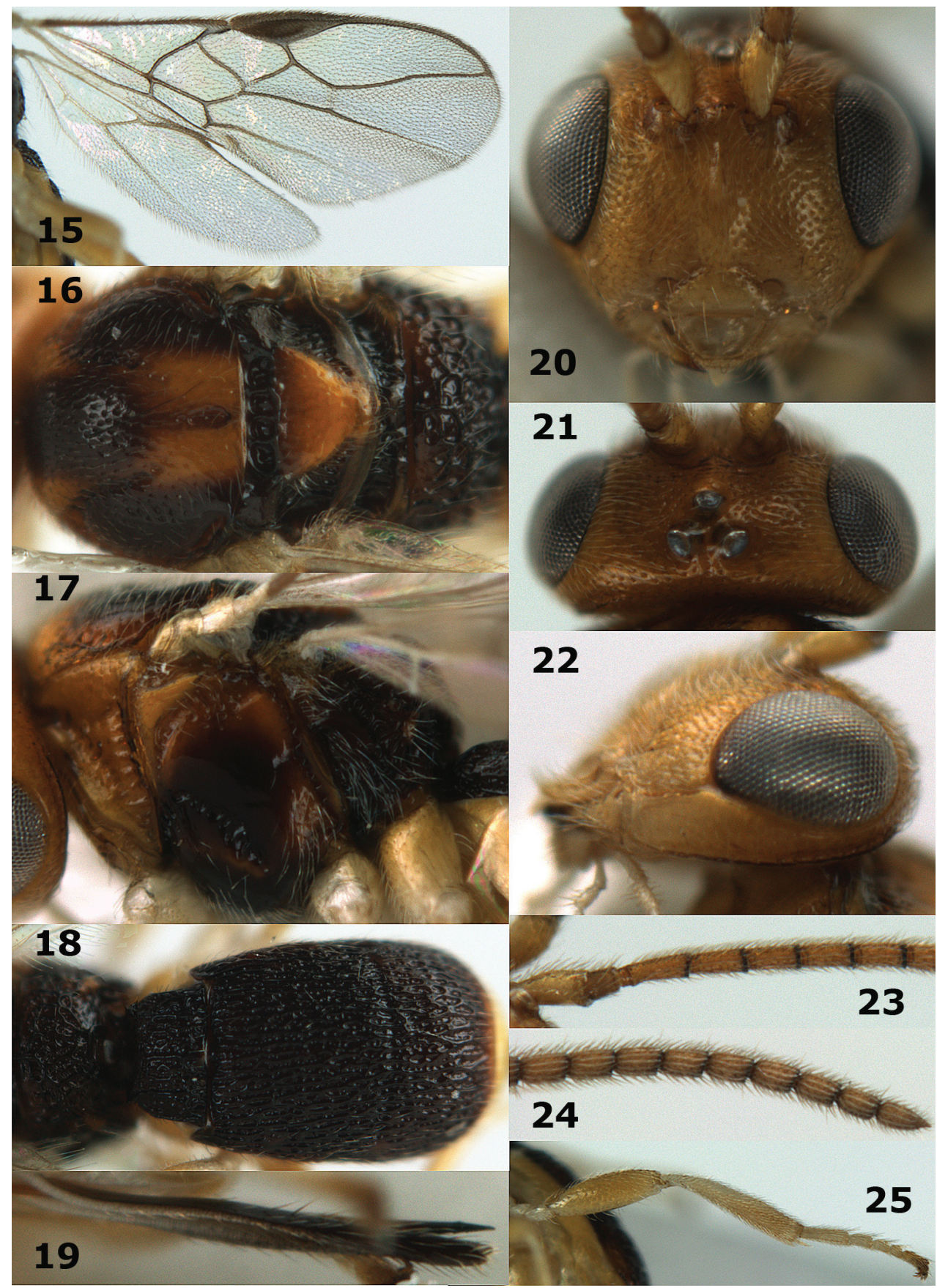

Figures 15-25. Orientopius europaeus sp. n., female, holotype. $\mathbf{5}$ wings $\mathbf{1 6}$ mesosoma dorsal $\mathbf{I 7}$ mesosoma lateral $\mathbf{1} \mathbf{8}$ metasoma dorsal $\mathbf{1 9}$ ovipositor sheath lateral $\mathbf{2 0}$ head anterior $\mathbf{2 1}$ head dorsal $\mathbf{2 2}$ malar space $\mathbf{2 3}$ base of antenna $\mathbf{2 4}$ apex of antenna $\mathbf{2 5}$ hind leg. 
Gumez", "pupe le 1-VI-1989, éclos sous abri le 2-VI.1989", "Ex pupe de Phytobia carbonaria prélevée sous un Crataegus monogyna"; 1 q, id., but emerged 19.VI.1989; 1 +, "[N. France], Aisne (02), forêt domaniale de Samoussy, J.L. Gumez", "pupe le 26V-1989, éclos sous abri le 20.VI.1989", "Ex pupe de Phytobia carbonaria prélevée sous un Crataegus monogyna"; 3 +, "[N. France], Aisne (02), Bouconville-Vauclair, forêt domaniale de Vauclair, J.L. Gumez", "pupes les 19 et 20-V-1990, éclos sous abri le 11VI-1990", "Ex pupes de Phytobia carbonaria sur Crataegus monogyna”; 2 , id., but emerged 12.VI.1990; 2 ㅇ, "[N. France, Aisne], 02, forêt [domaniale] de Vauclair, J.L. Gumez", "ex pupe de Phytobia sur Crataegus monogyna", "pupe le 19 et 23.V[I].1990, éclos [sous] abri [le] 11.VI.1990"; 1 +, "[N. France, Aisne, 02, forêt domaniale de Vauclair, J.L. Gumez] CN E1", "ex [pupe de] P[hytobia] carbonaria [sur Crataegus monogyna]", "[éclos sous abri le] 15.VI.1990".

Diagnosis. Vein SR1 ends near apex of fore wing (Figs 15, 32); vertex moderately densely punctate, with interspaces mostly equal to diameter of punctures or wider (Fig. 21); antenna yellowish-brown; pterostigma dark brown; second tergite 1.7-1.9 times as long as third tergite; third tergite 0.5 times longer than its basal width; third metasomal tergite subparallel-sided, subrectangular and densely reticulate-rugose (Figs 18, 33); fourth tergite of female smooth and retracted (Figs 1, 2, 32); setose part of ovipositor sheath 0.6-0.7 times as long as combined first-third metasomal tergites, 0.3 times as long as fore wing and 1.0-1.1 times as long as hind tibia (Fig. 32).

Description. Holotype, + , length of body $2.8 \mathrm{~mm}$, of fore wing $2.5 \mathrm{~mm}$.

Head. Antenna with 28 segments and 1.2 times as long as fore wing; third segment 1.3 times as long as fourth segment, length of third, fourth and penultimate segments $3.1,2.5$ and 1.5 times their width, respectively; length of maxillary palp 0.9 times height of head; labial palp segments slender; occipital carina widely removed from hypostomal carina and dorsally absent; hypostomal carina narrow; length of eye in dorsal view 7.3 times temple; temples directly narrowed (Fig. 21) and largely sparsely punctulate; frons slightly depressed behind antennal sockets and with some rugulae, remainder slightly convex and setose, largely coarsely punctate, with interspaces mostly somewhat wider than punctures; face medio-dorsally elevated, coarsely punctate, with interspaces slightly wider than punctures and some rugae latero-dorsally; width of clypeus 2.7 times its maximum height and 0.55 times width of face; clypeus flat, smooth and its ventral margin rather thin and medially straight; hypoclypeal depression wide and deep (Fig. 20); labrum flat but with upcurved rim; malar suture complete; with punctures between malar suture and clypeus; length of malar space 1.3 times basal width of mandible (Fig. 22); mandible strongly constricted and twisted apically, without distinct ventral carina (Fig. 22), second tooth medium-sized.

Mesosoma. Length of mesosoma 1.2 times its height; dorsal pronope not visible because of head, but in paratypes obsolescent, small and round; pronotum short and steep anteriorly; pronotal sides smooth but oblique and posterior grooves coarsely crenulate (Fig. 17); epicnemial area crenulate dorsally; precoxal sulcus distinctly im- 


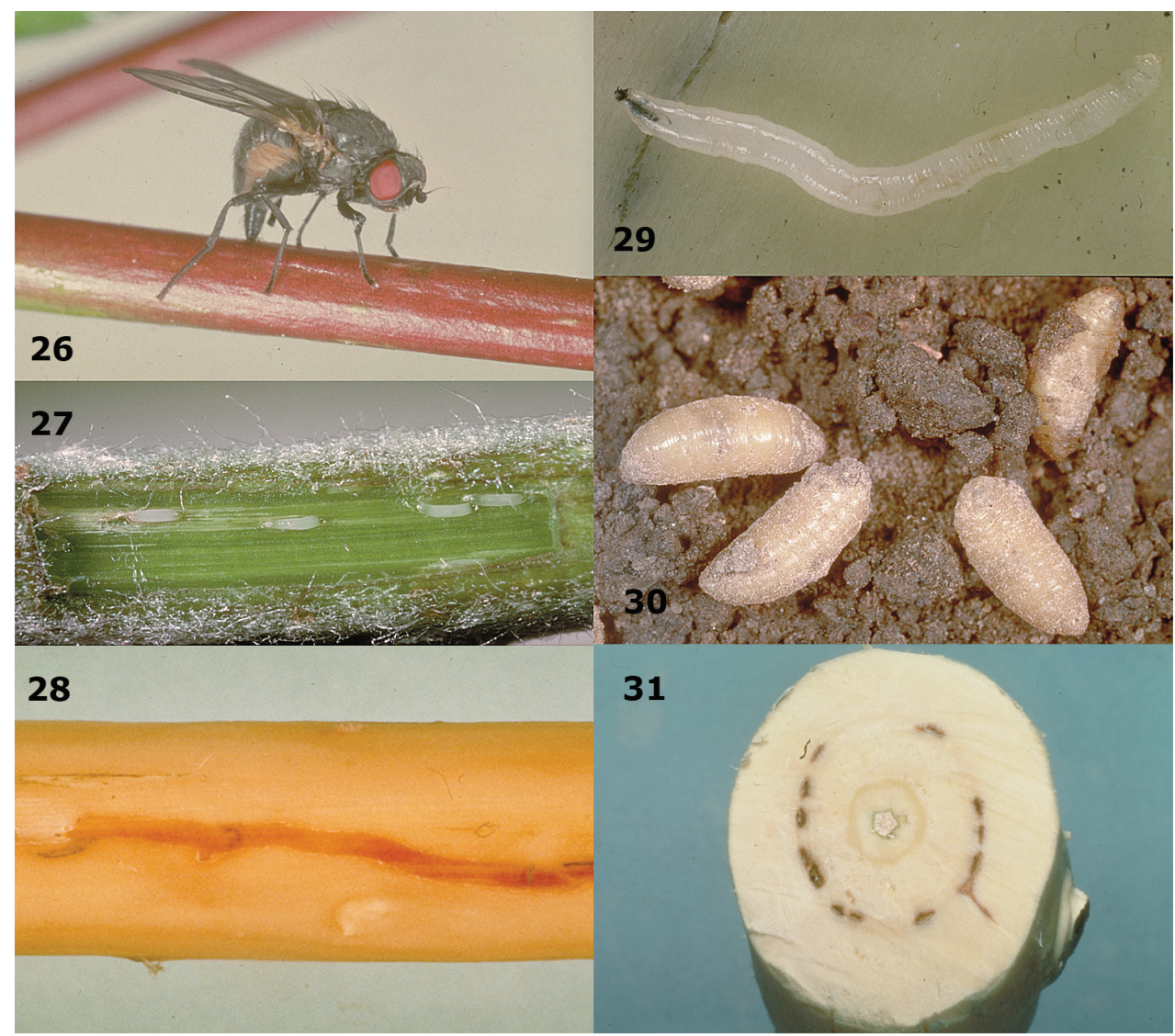

Figures 26-3 I. Phytobia cambii (Hendel) in Populus x canadensis. 26 adult ovipositing in young twig $\mathbf{2 7}$ tunnels inside twig $\mathbf{2 8}$ tunnel made by larva $\mathbf{2 9}$ larva $\mathbf{3 0}$ puparia $\mathbf{3 I}$ transverse section of tunnels made by larvae. Photographs by N. R. Coutin.

pressed, but absent posteriorly, and coarsely crenulate (Fig. 17); pleural sulcus distinctly crenulate; mesosternal sulcus deep and coarsely crenulate; postpectal carina only medio-ventrally present; metapleuron coarsely punctate-reticulate, but medially smooth; notauli crenulate and largely present on disk, only posteriorly absent near elongate elliptical medio-posterior depression mesoscutum setose and punctulate, but middle lobe largely moderately punctate; scutellar sulcus wide and with 3 coarse crenulae (Fig. 16); scutellum rather flat and sparsely punctulate; metanotum with complete median carina; surface of propodeum coarsely reticulate (Fig. 16).

Wings. Fore wing (Fig. 15): pterostigma elliptical; 1-R1 ending close to wing apex and 1.3 times as long as pterostigma; r:3-SR:SR1 = 5:15:49; 2-SR:3-SR:r-m = 17:15:7; $\mathrm{r}$ slender; 1-M and SR1 slightly curved; $\mathrm{m}$-cu just postfurcal; cu-a slightly postfurcal and 1-CU1 hardly widened; first subdiscal cell closed, CU1b medium-sized; M+CU1 sclerotized. Hind wing: M+CU:1-M:1r-m = 25:18:14; cu-a straight; $\mathrm{m}-\mathrm{cu}$ absent. 


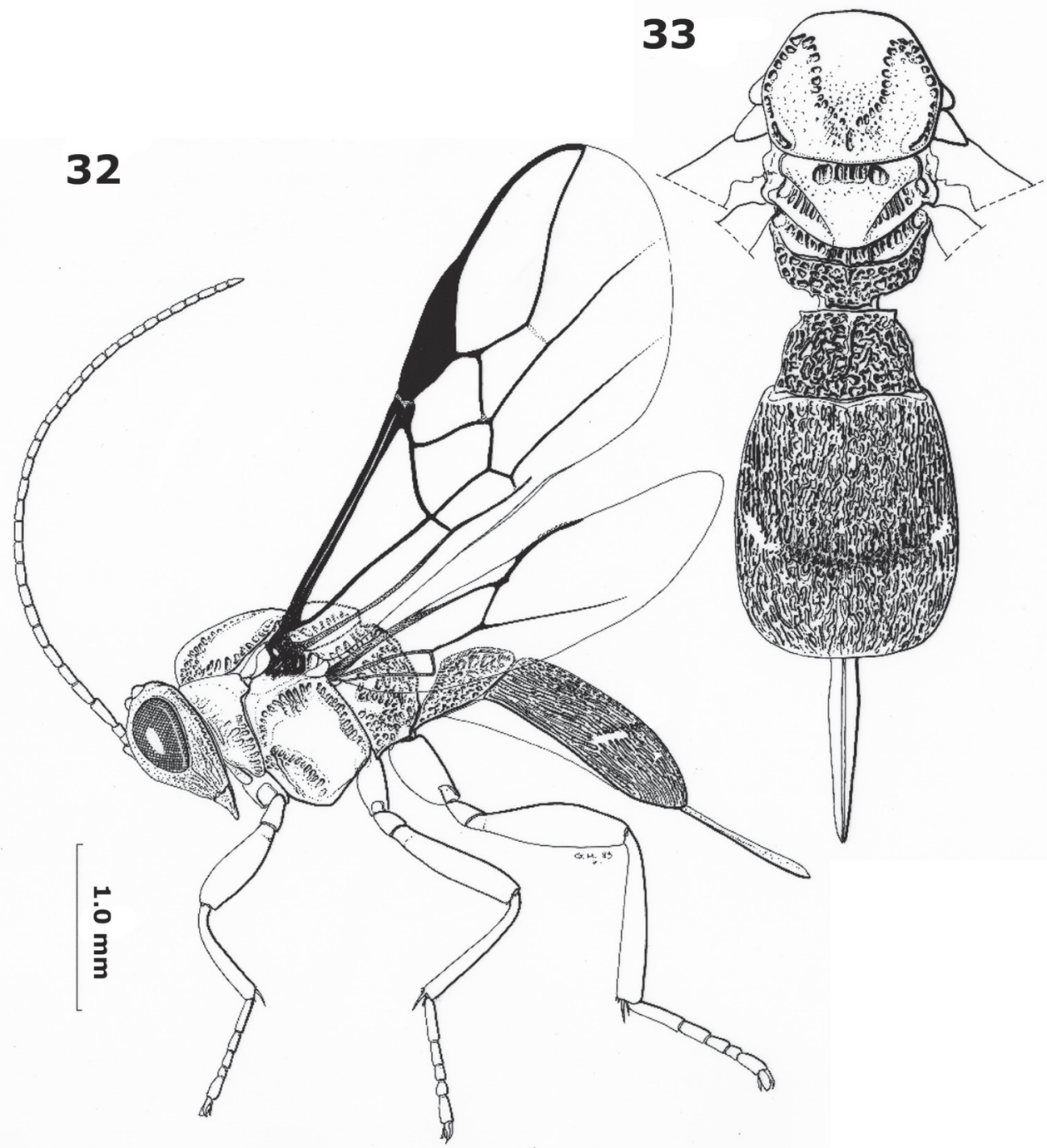

Figures 32-33. Orientopius europaeus sp. n., female. Habitus lateral and dorsal, respectively. Drawings by Gilbert Hodebert.

Legs. Length of femur, tibia and basitarsus of hind leg 3.0, 5.9 and 3.4 times as long as wide, respectively (Fig. 25); hind femur with medium-sized setae and tibia densely short setose; third and fourth segments of fore tarsus about as long as wide.

Metasoma. Length of first tergite 0.8 times its apical width, its surface punctate in front of dorsal carinae and longitudinally reticulate behind carinae, convex and dorsal carinae united and with median carina posteriorly (Fig. 18); second suture crenulate, nearly straight and moderately impressed; second and third tergites longitudinally reticulate-rugose; median length of second tergite 1.7 times median length of third 
tergite; following tergites smooth and largely retracted below carapace; length of setose part of ovipositor sheath 0.32 times fore wing, 0.6 times first-third tergites combined and 1.1 times longer than hind tibia; hypopygium far retracted, truncate apically and about 0.3 times as long as metasomal carapace.

Colour. Dark brown (including pterostigma and veins); antenna (but scapus yellow), mesoscutum (but laterally and antero-medially dark brown), scutellum and mesopleuron dorsally, posteriorly and narrowly below precoxal sulcus yellowishbrown; head and mandible yellow; ovipositor sheath blackish; clypeus, labrum, palpi, tegulae and legs (but telotarsi slightly darkened) pale yellow; wing membrane slightly infuscate.

Variation. Length of fore wing 2.5-3.2 $\mathrm{mm}$ and of body $2.8-3.4 \mathrm{~mm}$, antenna of female with 28 (1), 30 (3) or 31 (7) segments, vein 3-SR of fore wing 0.7-0.9 times as long as vein 2-SR; setose part of ovipositor sheath $0.29-0.32$ times as long as fore wing.

Distribution. Bulgaria, France.

Biology. Reared from puparia of Agromyzidae (Diptera) cambium miners, Phytobia carbonaria (Zetterstedt, 1848) in Crataegus monogyna and Phytobia cerasiferae (Kangas, 1955) in Prunus spinosa.

Etymology. Name derived from "Europa", because it is the first species of this genus known from Europe.

Notes. The species can be separated from the other (all East) Palaearctic species as follows:

$1 \quad$ Vein SR1 removed from apex of fore wing; vertex densely sculptured, with interspaces less than diameter of punctures . O. sculpticapitis Tobias, 1998

- Vein SR1 ends near apex of fore wing (Fig. 15); vertex less densely sculptured, with interspaces at least equal to diameter of punctures (Fig. 21) ................2

2 Third metasomal tergite subparallel-sided, subrectangular (Fig. 18); antenna yellowish-brown; pterostigma dark brown; fourth tergite smooth and more or less retracted (Figs 1, 2) ........................................................................ 3

- Third tergite roundly narrowed laterally, semicircular; colour of antenna and of pterostigma and sculpture of fourth tergite variable ................................ 4

3 Second metasomal tergite about 1.3 times as long as third tergite; third tergite 0.6 times longer than its basal width; setose part of ovipositor sheath as long as combined first-third metasomal tergites; East Palaearctic

O. quadratus Tobias, 1998

- $\quad$ Second tergite 1.7-1.9 times as long as third tergite (Fig. 18); third tergite 0.5 times longer than its basal width; setose part of ovipositor sheath 0.6-0.7 times as long as combined first-third metasomal tergites (Figs 1, 2); West Palaearctic

O. europaeus van Achterberg, sp. n. Fourth metasomal tergite largely smooth; second and third tergites partly smooth O. semilissus Tobias, 1998

- $\quad$ Fourth tergite distinctly sculptured; second and third tergites evenly sculptured. 
5 Second and third metasomal tergites mainly rugose-punctate, with only a few striae; fourth tergite punctate and no striae; antenna yellow and apically brownish; pterostigma yellow. O. flavicornis Tobias, 1998

- $\quad$ Second and third tergites distinctly striate; fourth tergite with striae; antenna dark brown, but yellowish in O. flavicapitis; pterostigma brown. 6

6 Precoxal sulcus extensively punctate; second and third metasomal tergites finely striate; setose part of ovipositor sheath about half as long as metasoma; dorsal half of head blackish O. belokobylskii Tobias, 1998

- $\quad$ Precoxal sulcus rugose medially; second and third metasomal tergites distinctly striate; setose part of ovipositor sheath about as long as metasoma; dorsal half of head yellowish. First metasomal tergite with strong rugae; mesosoma blackish or largely so; antenna largely yellowish O. flavicapitis Tobias, 1998

- $\quad$ First tergite without strong rugae; mesosoma largely brownish-yellow; antenna largely yellowish-brown, apically brown ....... O. nadezhdae Tobias, 1998

\section{Other Braconidae reared from Phytobia spp. in North France}

\section{Alysiinae-Dacnusini}

Epimicta marginalis (Haliday, 1839)

Reared from Phytobia carbonaria in Sorbus aucuparia Linnaeus and in Crataegus monogyna. First record of a host of this species.

Trachionus hians (Nees, 1816)

Reared from Phytobia cambii (Hendel, 1931) in Populus x canadensis [cv. "robusta"] and in Betula verrucosa Linnaeus.

Trachionus pappi (Zaykov, 1982)

Reared from Phytobia cerasiferae in Prunus spinosa. Trachionus pappi is new for France and this is the first host record for this species.

Trachionus ringens (Haliday, 1834)

Reared from Phytobia cambii in Populus x canadensis [cv. "robusta"] and Carpinus betulus Linnaeus.

\section{References}

Achterberg C van (1988) Revision of the subfamily Blacinae Foerster (Hymenoptera, Braconidae). Zoologische Verhandelingen Leiden 249: 1-324. 
Achterberg C van (1990) Illustrated key to the subfamilies of the Holarctic Braconidae (Hymenoptera: Ichneumonoidea). Zoologische Mededelingen Leiden 64: 1-20.

Achterberg C van (1993) Illustrated key to the subfamilies of the Braconidae (Hymenoptera: Ichneumonoidea). Zoologische Verhandelingen Leiden 283: 1-189.

Achterberg C van (1997) Braconidae. An illustrated key to all subfamilies. ETI World Biodiversity Database CD-ROM Series Amsterdam.

Chen J-H, Weng R-Q (2005) Systematic studies on Opiinae of China (Hymenoptera: Braconidae). Fujian Science and Technology Publishing House, Fujian, i-iii, 1-2, 1-9, 1-269.

Fischer M (1966) Revision der indo-australischen Opiinae (Hymenoptera, Braconidae). Dr. W. Junk, Den Haag, 165 pp.

Fischer M (1972) Hymenoptera Braconidae (Opiinae I). (Paläarktische Region). Das Tierreich 91: i-xii + 1-620.

Fischer M (1977) Hymenoptera Braconidae (Opiinae II). (Amerika). Das Tierreich 96: 1-1001.

Fischer M (1986) Neue Bestimmungsschlüssel für paläarktische Opiinae, neue Subgenera, Redeskriptionen und eine neue Art (Hymenoptera, Braconidae). Annalen des Naturhistorischen Museums in Wien 88/89: 607-662.

Fischer M (1987) Hymenoptera Braconidae (Opiinae III) - äthiopische, orientalische, australische und ozeanische Region. Das Tierreich 104: $\mathrm{i}-\mathrm{xv}+1-734$.

Tobias VI (1998) Opiinae. In: Ler PA (Ed) Key to the insects of Russian Far East. 4. Neuropteroidea, Mecoptera, Hymenoptera 3. Dal'nauka, Vladivostok, 558-655.

Yu DS, Achterberg K van, Horstmann K (2009) Biological and taxonomical information: Ichneumonoidea 2006 (updated version). Taxapad Interactive Catalogue, Lexington. 